Article

\title{
Factors Influencing Decision Making Regarding the Acceptance of the COVID-19 Vaccination in Egypt: A Cross-Sectional Study in an Urban, Well-Educated Sample
}

\author{
Mohamed Elsayed 1,*, Radwa Abdullah El-Abasiri ${ }^{2}\left(\mathbb{D}\right.$, Khaled T. Dardeer ${ }^{3}$, Manar Ahmed Kamal $4{ }^{4}$, \\ Mila Nu Nu Htay ${ }^{5}$, Birgit Abler ${ }^{1}$ and Roy Rillera Marzo ${ }^{6,7}$ (D) \\ 1 Department of Psychiatry and Psychotherapy III, University of Ulm, Leimgrubenweg 12-14, \\ 89075 Ulm, Germany; birgit.abler@uni-ulm.de \\ 2 Nuffield Department of Population Health, Old Road Campus, University of Oxford Richard Doll Building, \\ Oxford OX3 7LF, UK; radwa.el-abasiri@dph.ox.ac.uk \\ 3 Faculty of Medicine, Cairo University, Cairo 11562, Egypt; khaledegy99@gmail.com \\ 4 Faculty of Medicine, Benha University, Benha 13511, Egypt; manarahmedkamal37@gmail.com \\ 5 Department of Community Medicine, Manipal University College Malaysia, Manipal Academy of Higher Education, \\ Melaka 75150, Malaysia; drmlnnh@gmail.com \\ 6 Department of Community Medicine, International Medical School, Management and Science University, \\ Shah Alam 40100, Malaysia; rrmtexas@yahoo.com \\ 7 Global Public Health, Jeffrey Cheah School of Medicine and Health Sciences, Monash University Malaysia, \\ Petaling Jaya 46150, Malaysia \\ * Correspondence: mohamed.elsayed@mein.gmx
}

\section{check for}

updates

Citation: Elsayed, M.; El-Abasiri, R.A.; Dardeer, K.T.; Kamal, M.A.; Htay, M.N.N.; Abler, B.; Marzo, R.R. Factors Influencing Decision Making Regarding the Acceptance of The COVID-19 Vaccination in Egypt: A Cross-Sectional Study in an Urban, Well-Educated Sample. Vaccines 2022, 10, 20. https://doi.org/10.3390/ vaccines 10010020

Academic Editor: Brian D. Poole

Received: 25 November 2021

Accepted: 21 December 2021

Published: 24 December 2021

Publisher's Note: MDPI stays neutral with regard to jurisdictional claims in published maps and institutional affiliations.

Copyright: (C) 2021 by the authors. Licensee MDPI, Basel, Switzerland. This article is an open access article distributed under the terms and conditions of the Creative Commons Attribution (CC BY) license (https:// creativecommons.org/licenses/by/ $4.0 /)$.

\begin{abstract}
Background: The COVID-19 pandemic has raised the necessity to rapidly develop safe and effective vaccines to limit the spread of infections. Meanwhile, vaccine hesitancy is a significant barrier to community vaccination strategies. Methods: An internet-based cross-sectional survey was conducted from March to April 2021 during the start of the vaccination campaigns. Results: A total of 1009 subjects participated, and the mean age $( \pm \mathrm{SD})$ was $29.11 \pm 8.2$ years. Among them, $68.8 \%$ believed that vaccination is an effective method to control the spread of the disease, $81.2 \%$ indicated acceptance of the vaccine, and $87.09 \%$ reported that their doctor's recommendation was essential for decision making. After adjusting for socioeconomic characteristics, rural residency (AOR 1.783, 95\%CI: 1.256-2.531), working a part-time job (AOR 2.535, 95\%CI: 1.202-5.343) or a full-time job (AOR 1.951, 95\%CI: 1.056-3.604), being a student (AOR 3.516, 95\%CI: 1.805-6.852) and having a partner (AOR 1.457,95\%CI: 1.062-2.00) were significant predictors for higher vaccine acceptance among the study participants. Believing in the vaccine's efficacy showed the strongest correlation with vaccine acceptance (Spearman's $r=0.309, p<0.001)$. Conclusions: Although general vaccine acceptance is high $(32.85 \%)$ in participants in our study, gender and geographic disparities were observed in the investigated urban population of young, well-educated Egyptians.
\end{abstract}

Keywords: vaccine; COVID-19; Egypt; intention; accepting; factors

\section{Introduction}

The severe acute respiratory syndrome coronavirus 2 (SARS-CoV-2) caused the emergence of the ongoing coronavirus disease 2019 (COVID-19) pandemic [1-4]. SARS-CoV-2 spread rapidly to 223 countries [1,2]. As of 24 September 2021, the COVID-19 pandemic has caused more than 442 million infections [5]. SARS-CoV-2 can induce life-threatening complications, such as fever, dyspnoea, cough, and acute respiratory distress [6]. The COVID-19 outbreak raised the necessity to rapidly develop efficient and safe vaccines to limit the spread of this infection [7]. However, despite the serious pandemic situation, the willingness of the Egyptian people to receive a vaccine against COVID-19 is still unclear. Vaccine hesitancy is a significant barrier to vaccination campaigns, as it obstructs the process of achieving herd immunity [8]. The initial strategy used by most countries worldwide 
was reducing disease transmission by mask policies, social distancing, hand sanitization, travel restrictions, and lockdowns [9]. Despite the success of the measures mentioned above to slow down the disease spread, vaccination remains the most influential factor in decreasing morbidity and mortality [10]. Vaccines are reliable, cost-effective public health interventions that save millions of lives annually [11-13]. A worldwide race to develop a vaccine against SARS-CoV2 started after the emergence of the COVID-19 pandemic [14]. Up to now, at least ten COVID-19 vaccines were emergency authorized [15] with the hope of ending the pandemic via herd immunity $[14,16]$. The worldwide vaccine skepticism and hesitancy are the main obstacles to rapidly reaching herd immunity [17-19]. The World Health Organization (WHO) defined Vaccine Hesitancy as a "delay in acceptance or refusal of vaccination despite the availability of vaccination services" [18]. The acceptance of vaccines depends on trust in the safety and effectiveness of the vaccine and other factors, such as the political and healthcare system [20].

Until mid-September 2021, Egypt reported almost 300,000 confirmed cases of COVID-19 and over 17,000 deaths to the WHO. As of mid-September 2021, a total of nearly 13 million vaccine doses have been administered [21]. Assuming every person needs two doses, about $6.5 \%$ of the country's population could have received the vaccine by then [22]. A web-based questionnaire in Italy of over 3000 participants from March to April 2021 showed that $91.9 \%$ were keen to receive a COVID vaccination [23]. An anonymous crosssectional survey among over 2000 Chinese adults in March 2020 showed an acceptance rate of $91.3 \%$ to be vaccinated against COVID-19 [24]. A cross-sectional study previously investigated vaccine hesitance during the pandemic in Egyptian healthcare workers [25]. In the study conducted from 30th March to the end of April 2021, only $26 \%$ of participants were willing to be vaccinated, while $41.9 \%$ were hesitant, and $32.1 \%$ refused to be given the vaccine [26]. The current literature lacks adequate information about the potential factors that might influence vaccination against COVID-19 in the Egyptian population. Therefore, the current study investigated the factors that influence vaccine apprehension in an Egyptian community sample. This study aims to assess the COVID-19 vaccine acceptance among an Egyptian sample, highlight the factors that may influence the decision to be vaccinated against COVID-19 and raise more attention to the importance of identifying such factors. Examining the variables that affect positive and negative attitudes toward or against vaccination against COVID-19 is important for the authorities to adjust campaigns to broaden the COVID-19 vaccination quota in Egypt and address the specific concerns of hesitant risk groups.

\section{Materials and Methods}

\subsection{Study Setting and Population}

During the vaccine campaigns starting, an internet-based cross-sectional survey was conducted from March to April 2021, with the health ministry calling the population to be vaccinated. The Egyptian health ministry did not announce the vaccination quota when conducting this study. However, only medical personnel were eligible for vaccination at the time of the study. Snowball sampling was chosen as a convenient sampling method for data collection in private and business networks of colleges and their relatives. The study population was adults aged 18 to 65 years who resided in Egypt during the period mentioned above and were not eligible for vaccination at the survey time. The survey was sent online to avoid increased human contact and limit the infection rates. The structured online survey was in English and distributed through electronic mail, WhatsApp, Telegram, and other social media platforms throughout Egypt. Co-researchers and colleagues identified each respondents' social media account through their links and networking. The survey was blinded so that the responses were not identifiable. In addition, the records were secured through password-protected files and with encryption when sending information over the internet to keep the participant's identity confidential. 


\subsection{Ethical Considerations}

Ethical approval was granted from the Research Ethics Committee from Asia Metropolitan University (Ethics Approval Number: AMU/FOM/NF 202115). The recruitment procedure complied with the declaration of Helsinki regarding research on human subjects. All participants participated voluntarily and gave their informed consent before filling the survey.

\subsection{Study Tool}

Data were collected through a structured online questionnaire (see Supplementary Material, File S1). The questionnaire has two parts: Section A: Sociodemographic data (age, gender, place of residency, race, educational level, occupational status, marital status, and family income). Section B: The acceptability and factors influencing the acceptability of COVID-19 vaccination, which consists of six closed-ended questions. The first and the second questions asked if the respondent believes that the COVID-19 vaccination is an effective way to prevent and control COVID-19 and if they will accept a vaccine when it is successfully developed and approved. The following three questions inquired about the factors affecting the vaccine's acceptability, such as method, frequency, distance to the vaccine sites, doctor's recommendation, and price. The last question asked subjects to check (yes or no) if the participant would accept the vaccine as soon as available or wait until further testing was performed.

A group of expert panelists in Egypt, including psychiatrists, clinical psychologists, physicians, specialists, pharmacists, clinicians, and public health experts, translated and culturally validated the questionnaire into Arabic (but the language later used during the data collection was English).

\subsection{Sample Size and Sampling}

Power analysis on this sample suggested a minimal sample size of 1000 participants to detect a meaningful impact size of $\delta=0.2(\alpha=0.05$; two-tailed). Hence, 1009 responses were received.

The questionnaire was pre-tested in a small sample of participants $(n=50)$ to confirm the practicability and clarity of questions. For content validity, the questionnaire was sent to three experts for revision, and their comments were taken in our consideration. For reliability, Cronbach's alpha was calculated based on the first 50 responses from the questionnaire, and it was equal to 0.673 . Cronbach's alpha was questionable, and the value was considered high reliability and acceptable.

\subsection{Statistical Analysis}

SPSS v25.0 software was used for the data analysis and reliability testing. Continuous variables were presented as mean \pm standard deviation (SD), while categorical variables were presented as number and percentage. The primary outcome was rapid acceptance or hesitancy toward COVID-19 vaccination as soon as it was available (response to question 6). Responses to questions 1 to 5 regarding the participants' personal beliefs about the COVID-19 vaccination were treated as secondary outcome variables. Binary logistic regression was conducted to analyze the predictive factors for vaccine acceptance among population characteristics. Univariate and multivariate analyses were conducted to obtain the odds ratios (OR) and adjusted odds ratios (AOR) with their $95 \%$ confidence interval. Chi-square (chi $\mathrm{x}^{2}$ ) and partial rank correlation tests were conducted after controlling for potential confounders to correlate the beliefs regarding the COVID-19 vaccine (Questions 1 to 5) and the acceptance of vaccination among study participants (Question 6). Spearman's $r$ with correspondent $p$ values were calculated. The $p$-values less than 0.05 were considered statistically significant. The correlation coefficient of \pm 0.1 was regarded as a weak correlation, \pm 0.3 as a moderate correlation and \pm 0.5 as a high correlation. The chi $x^{2}$ of 0.1 was considered a weak association, 0.3 as a moderate association and 0.5 as a high association. When the results of OR equal one, this means that the odds of the main category equaling the odds of the reference category; when the results of OR are less than one, this means that the odds of the main category are less than the odds of the reference 
category; and when the results of OR are more than one, this means that the odds of the main category are more than the odds of the reference category.

\section{Results}

\subsection{Population Characteristics}

A total of 1009 subjects responded to the survey. Forty-one participants did not consent to be included, leaving 968 individuals answering the questionnaire. Thus, the response rate was $95.9 \%$. The mean age of included participants was $29.11 \pm 8.2$ years, and two-thirds $(61.67 \%)$ were female. The majority were below 30 years old $(69.73 \%)$ and reported urban places of residence $(78.31 \%)$. Almost all of the participants were Egyptian (95.14\%). Two-thirds (62.5\%) worked a full-time job, and over half $(53.10 \%)$ reported an annual income of more than EGP 10,000. Two-thirds (62.71\%) were single with an education level of post-secondary (51.03\%) or higher $(45.76 \%)$.

In this concern, it is worth mentioning that the Egyptian population has a median age of 24,7 years [27], 42.78\% of the Egyptian's total population lives in urban areas and cities [28], the average annual income per household in Egypt is about EGP 59.7 thousand [29]. Thus, the representativity of the sample investigated might be limited, particularly concerning the overrepresentation of urban residency and higher education in this investigation.

A third (32.85\%) of participants responded that they would be willing to accept the COVID-19 vaccine as soon as possible (Question six: YES). In comparison, the rest $(67.15 \%)$ stated that they preferred to delay vaccination until the safety of the vaccines were confirmed (Question six: NO, Table 1).

Table 1. Baseline Demographic Characteristics of the Participants $(n=968)$.

\begin{tabular}{|c|c|c|}
\hline Characteristic & No. & $\%$ \\
\hline Age & 968 & \\
\hline Mean \pm SD & \multicolumn{2}{|c|}{$29.11 \pm 8.2$} \\
\hline Age Groups & 968 & \\
\hline Below 30 & 675 & 69.73 \\
\hline $30-59$ & 281 & 29.03 \\
\hline Over 60 & 12 & 1.24 \\
\hline Gender & 968 & \\
\hline Male & 371 & 38.33 \\
\hline Female & 597 & 61.67 \\
\hline Residency & 968 & \\
\hline Urban & 758 & 78.31 \\
\hline Rural & 210 & 21.69 \\
\hline Race & 968 & \\
\hline Egyptian & 921 & 95.14 \\
\hline Non Egyptian & 47 & 4.86 \\
\hline Education & 968 & \\
\hline Secondary or below & 31 & 3.20 \\
\hline Post-Secondary & 494 & 51.03 \\
\hline Tertiary & 443 & 45.76 \\
\hline Occupation & 968 & \\
\hline Unemployed & 94 & 9.71 \\
\hline Part-time & 82 & 8.47 \\
\hline Full time & 605 & 62.50 \\
\hline Student & 187 & 19.32 \\
\hline
\end{tabular}


Table 1. Cont.

\begin{tabular}{ccc}
\hline Characteristic & No. & \% \\
\hline Marital status & 968 & \\
Single & 607 & 62.71 \\
With partner & 361 & 37.29 \\
\hline Monthly Income & 968 & \\
Less than 5 k & 122 & 12.60 \\
$5-10 \mathrm{k}$ & 332 & 34.30 \\
More than 10 k & 514 & 53.10 \\
\hline Vaccine acceptance & & \\
I will accept the vaccine as soon as it becomes available & 318 & 32.8 \\
Delay vaccination until I have confirmed the safety of the vaccine & 650 & 67.2 \\
\hline
\end{tabular}

\subsection{Beliefs about the Vaccination among Study Participants}

Two-thirds (68.8\%) of the participants believed the COVID-19 vaccine to be an effective method of controlling the spread of the disease (Question one). The majority (81.2\%) reported acceptance of the vaccine if the approval for listing was made (Question two). Vaccine convenience was stated as necessary by $85.54 \%$ of the study participants (Question three). A doctor's recommendation for vaccination was considered essential to facilitating decision making by $87.09 \%$ of respondents (Question four). The vaccination price was a concern in $74.69 \%$ of the study participants (Question five Table 2, Figure 1).

Table 2. Beliefs about the Vaccination among Study Participants $(n=968)$.

\begin{tabular}{|c|c|c|c|c|}
\hline \multirow{2}{*}{ Question Item } & \multicolumn{2}{|c|}{ No } & \multicolumn{2}{|c|}{ Yes } \\
\hline & No. & $\%$ & No. & $\%$ \\
\hline $\begin{array}{l}\text { COVID-19 vaccination is an effective way to prevent } \\
\text { and control COVID-19. }\end{array}$ & 302 & 31.20 & 666 & 68.80 \\
\hline $\begin{array}{c}\text { I would like to accept vaccination if the COVID-19 } \\
\text { vaccine is successfully developed and approved for } \\
\text { listing in the future. }\end{array}$ & 182 & 18.80 & 786 & 81.20 \\
\hline $\begin{array}{l}\text { Vaccine convenience (vaccination method, frequency, } \\
\text { and distance to vaccination sites) is an important } \\
\text { factor in vaccination decision making. }\end{array}$ & 140 & 14.46 & 828 & 85.54 \\
\hline $\begin{array}{c}\text { Doctor's recommendation is an important factor in } \\
\text { vaccination decision making. }\end{array}$ & 125 & 12.91 & 843 & 87.09 \\
\hline $\begin{array}{c}\text { Vaccine price is an important factor in vaccination } \\
\text { decision making. }\end{array}$ & 245 & 25.31 & 723 & 74.69 \\
\hline
\end{tabular}

\subsection{Predictors for Vaccine Acceptance among Population Characteristics}

Univariate analysis showed that rural residency, having a part-time or full-time job, and being a student were predictors for vaccine acceptance as assessed by Question six. Conversely, being a female was a significant factor for vaccine hesitancy (Question six: NO, delay vaccination until confirming the vaccine safety). After adjusting for socioeconomic characteristics, rural residency (AOR 1.783, 95\%CI: 1.256-2.531, $p=0.001$ ), working a part-time job (AOR 2.535, 95\%CI: 1.202-5.343 $p=0.015$ ) or a full time job (AOR 1.951, 95\%CI: 1.056-3.604, $p=0.033$ ), being a student (AOR 3.516, 95\%CI: 1.805-6.852, $p<0.001$ ) and having a partner (AOR 1.457, 95\%CI: $1.062-2, p=0.02$ ) were significant predictors for higher vaccine acceptance among study participants. On the other hand, being a female (AOR $0.36,95 \%$ CI: $0.27-0.481, p<0.001$ ) remained a predictive factor for vaccine hesitancy (Table 3, Figures 2-4). 


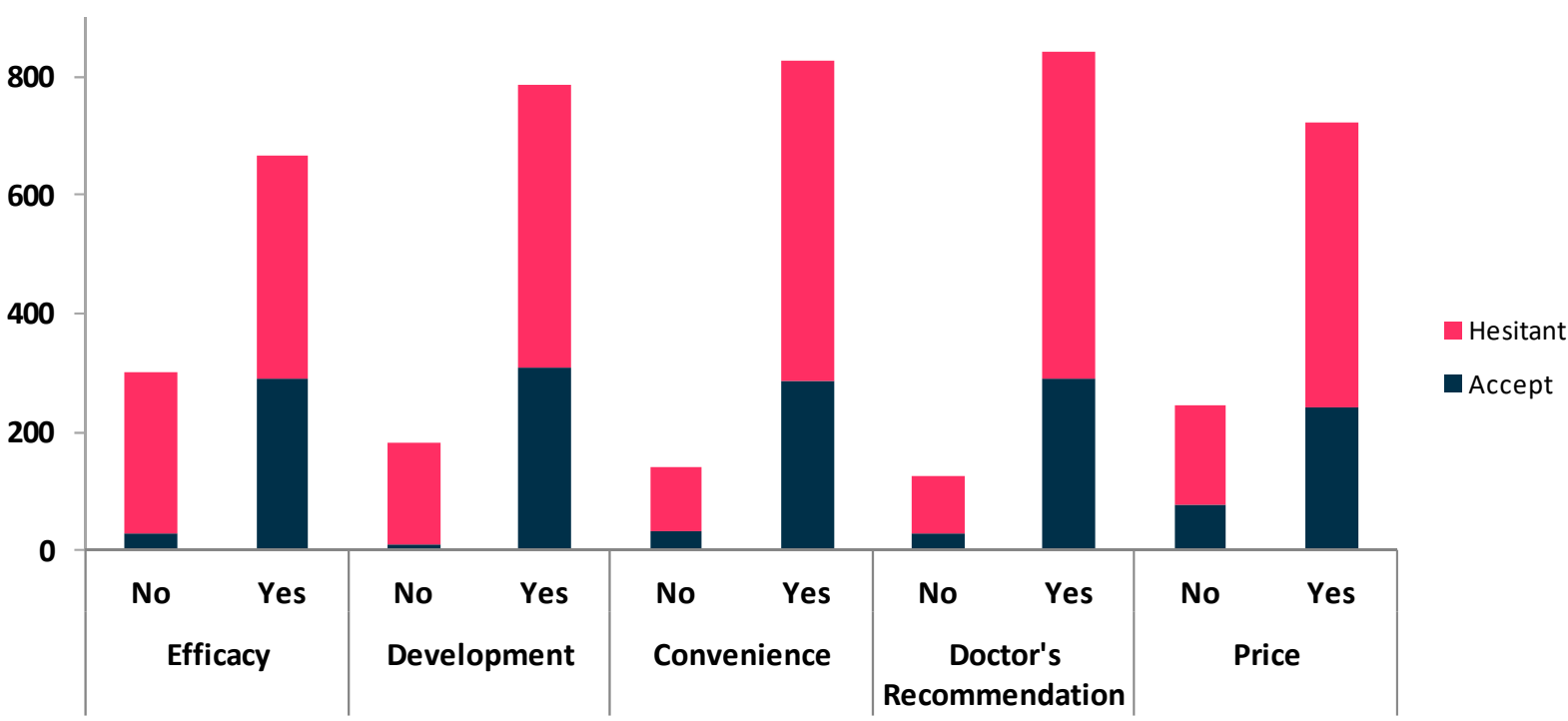

Figure 1. Beliefs about the vaccine and vaccination acceptance among study participants.

Table 3. Predictors for Vaccine Acceptance among Population Characteristics $(n=968)$. Bold type provide easier distinction between different Items.

\begin{tabular}{|c|c|c|c|c|c|c|c|c|c|c|c|c|}
\hline \multirow{2}{*}{ Characteristics } & \multicolumn{2}{|c|}{ Hesitant } & \multicolumn{2}{|c|}{ Accept } & \multicolumn{4}{|c|}{ Unadjusted Analysis } & \multicolumn{4}{|c|}{ Adjusted Analysis * } \\
\hline & $n$ & $\%$ & $n$ & $\%$ & $p$ & ORs & 95 & CI & $p$ & ORs & 95 & CI \\
\hline Age Groups & 650 & & 318 & & & & & & & & & \\
\hline Below 30 & 456 & 67.6 & 219 & 32.4 & Ref & & & & & & & \\
\hline $30-59$ & 186 & 66.2 & 95 & 33.8 & 0.683 & 1.063 & 0.792 & 1.428 & 0.746 & 0.944 & 0.665 & 1.339 \\
\hline Over 60 & 8 & 66.7 & 4 & 33.3 & 0.948 & 1.041 & 0.310 & 3.495 & 0.965 & 1.030 & 0.272 & 3.904 \\
\hline Gender & 650 & & 318 & & & & & & & & & \\
\hline Male & 198 & 53.4 & 173 & 46.6 & Ref & & & & & & & \\
\hline Female & 452 & 75.7 & 145 & 24.3 & $<0.001$ & 0.367 & 0.278 & 0.484 & $<0.001$ & 0.360 & 0.270 & 0.481 \\
\hline Residency & 650 & & 318 & & & & & & & & & \\
\hline Urban & 525 & 69.3 & 233 & 30.7 & Ref & & & & & & & \\
\hline Rural & 125 & 59.5 & 85 & 40.5 & 0.008 & 1.532 & 1.117 & 2.101 & 0.001 & 1.783 & 1.256 & 2.531 \\
\hline Nationality & 650 & & 318 & & & & & & & & & \\
\hline Egyptian & 621 & 67.4 & 300 & 32.6 & Ref & & & & & & & \\
\hline Non-Egyptian & 29 & 61.7 & 18 & 38.3 & 0.416 & 1.285 & 0.702 & 2.351 & 0.766 & 1.104 & 0.576 & 2.114 \\
\hline Education & 650 & & 318 & & & & & & & & & \\
\hline Secondary or below & 22 & 71 & 9 & 29.0 & Ref & & & & & & & \\
\hline Post-Secondary & 336 & 68 & 158 & 32.0 & 0.732 & 1.149 & 0.517 & 2.554 & 0.656 & 1.222 & 0.505 & 2.958 \\
\hline Tertiary & 292 & 65.9 & 151 & 34.1 & 0.566 & 1.264 & 0.568 & 2.813 & 0.414 & 1.466 & 0.586 & 3.666 \\
\hline Occupation & 650 & & 318 & & & & & & & & & \\
\hline Unemployed & 79 & 84 & 15 & 16.0 & Ref & & & & & & & \\
\hline Part time & 52 & 63.4 & 30 & 36.6 & 0.002 & 3.038 & 1.491 & 6.191 & 0.015 & 2.535 & 1.202 & 5.343 \\
\hline Full time & 407 & 67.3 & 198 & 32.7 & 0.001 & 2.562 & 1.438 & 4.565 & 0.033 & 1.951 & 1.056 & 3.604 \\
\hline Student & 112 & 59.9 & 75 & 40.1 & $<0.001$ & 3.527 & 1.888 & 6.587 & $<0.001$ & 3.516 & 1.805 & 6.852 \\
\hline Marital status & 650 & & 318 & & & & & & & & & \\
\hline Single & 414 & 68.2 & 193 & 31.8 & Ref & & & & & & & \\
\hline With partner & 236 & 65.4 & 125 & 34.6 & 0.365 & 1.136 & 0.862 & 1.497 & 0.020 & 1.457 & 1.062 & 2.000 \\
\hline Monthly Income & 650 & & 318 & & & & & & & & & \\
\hline Less than $5 \mathrm{k}$ & 87 & 71.3 & 35 & 28.7 & Ref & & & & & & & \\
\hline $5 \mathrm{k}-10 \mathrm{k}$ & 222 & 66.9 & 110 & 33.1 & 0.368 & 1.232 & 0.782 & 1.939 & 0.130 & 1.466 & 0.894 & 2.404 \\
\hline More than $10 \mathrm{k}$ & 341 & 67.6 & 173 & 33.7 & 0.294 & 1.261 & 0.818 & 1.944 & 0.075 & 1.553 & 0.956 & 2.522 \\
\hline
\end{tabular}



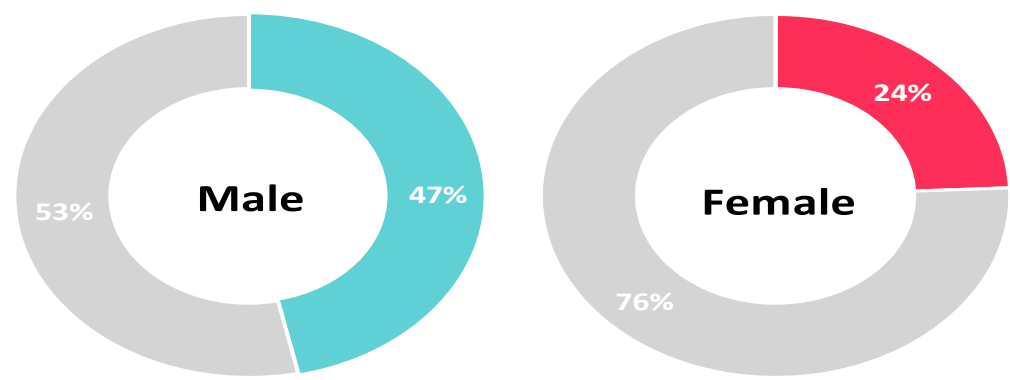

Figure 2. Vaccine acceptance and gender (colored section: percentage of participants that would accept the vaccine).
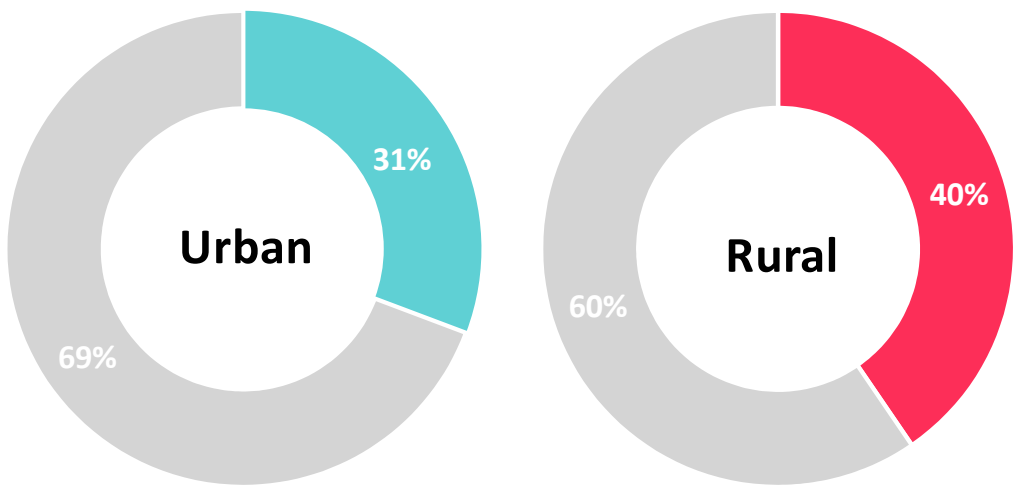

Figure 3. Vaccine acceptance and residency (colored section: percentage of participants that would accept the vaccine).
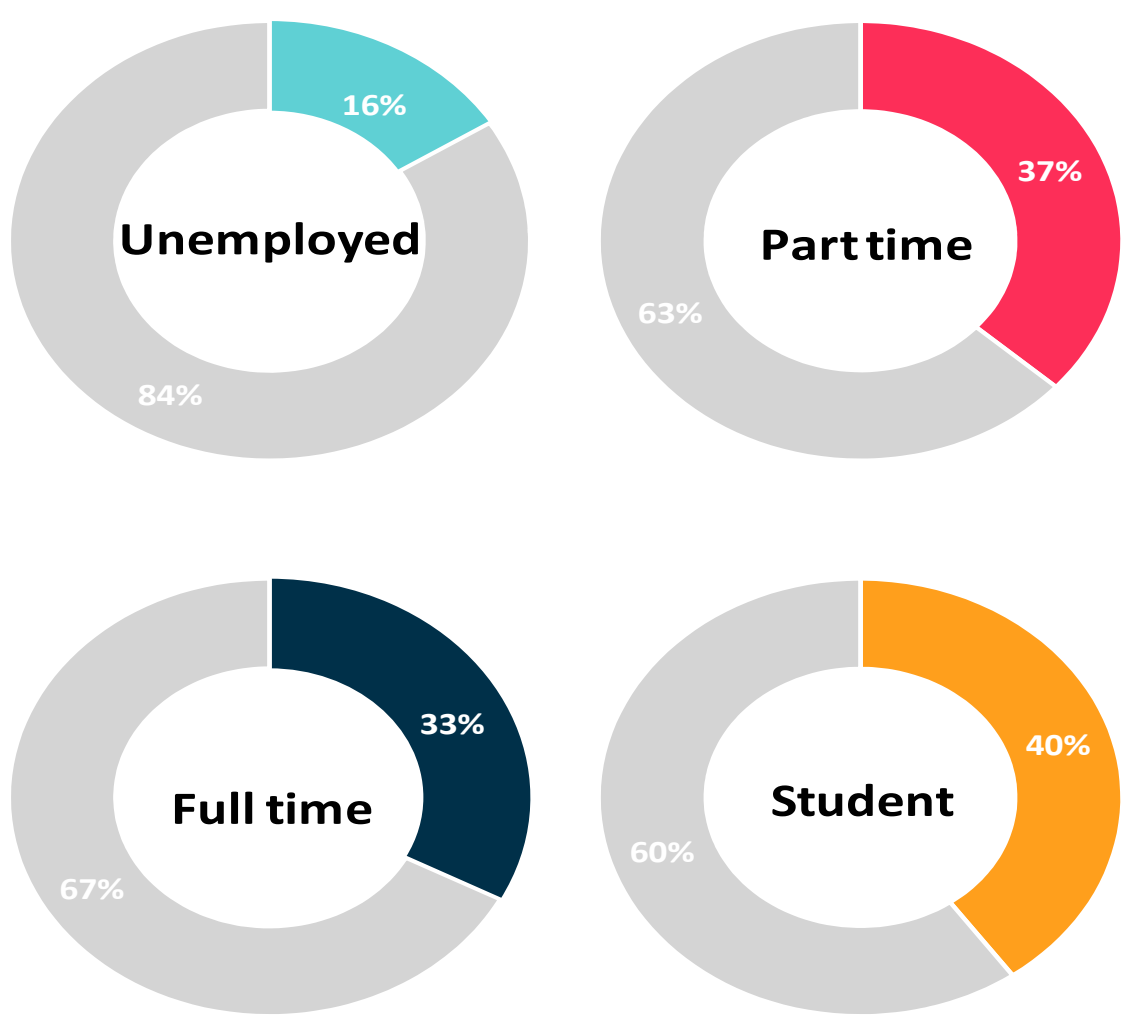

Figure 4. Vaccine acceptance and occupational status (colored section: percentage of participants that would accept the vaccine). 


\subsection{Correlation between Beliefs about the Vaccine and Acceptance towards Vaccination}

After controlling for the significant variables in the binary logistic regression model, a partial rank correlation test was conducted. Believing in the efficacy of the vaccine in controlling COVID-19 (Question one) and the development and approval of the listing of the COVID-19 vaccination (Question two) showed the strongest correlation with vaccine acceptance among the study participants (Spearman's $r=0.309$ and 0.277, $p<0.001$, respectively). Convenience issues regarding vaccination (Question three) showed a weak but significant correlation with vaccine acceptance (Spearman's $r=0.078, p=0.016$ ). The doctor's recommendation and the price of the vaccine did not affect the decision regarding vaccination (Question five) among study participants (Spearman's $r=0.061$ and 0.021, $p=0.058$ and 0.518 , respectively) (Table 4 ).

Table 4. Correlation between Beliefs about the vaccine and Acceptance towards Vaccination $(n=968)$. Bold type provide easier distinction between different Items.

\begin{tabular}{|c|c|c|c|c|c|c|c|c|}
\hline \multirow{2}{*}{ Belief about Vaccine } & \multicolumn{2}{|c|}{ Hesitant } & \multicolumn{2}{|c|}{ Accept } & \multirow{2}{*}{$\mathrm{Chi}^{2}$} & \multirow{2}{*}{$p$} & \multirow{2}{*}{ Spearman's $r$} & \multirow{2}{*}{$p$} \\
\hline & $n$ & $\%$ & $n$ & $\%$ & & & & \\
\hline Efficacy & 650 & & 318 & & \multirow{3}{*}{104.508} & \multirow{3}{*}{$<0.001$} & \multirow[b]{3}{*}{0.309} & \multirow[b]{3}{*}{$<0.001$} \\
\hline No & 272 & 90.1 & 30 & 9.9 & & & & \\
\hline Yes & 378 & 56.8 & 288 & 43.2 & & & & \\
\hline Development & 650 & & 318 & & & & & \\
\hline No & 171 & 94.0 & 11 & 6.0 & \multirow{2}{*}{73.02} & \multirow{2}{*}{$<0.001$} & \multirow{2}{*}{0.277} & \multirow{2}{*}{$<0.001$} \\
\hline Yes & 479 & 60.9 & 307 & 39.1 & & & & \\
\hline Convenience & 650 & & 318 & & \multirow{3}{*}{6.389} & \multirow{3}{*}{0.011} & \multirow{3}{*}{0.078} & \multirow{3}{*}{0.016} \\
\hline No & 107 & 76.4 & 33 & 23.6 & & & & \\
\hline Yes & 543 & 65.6 & 285 & 34.4 & & & & \\
\hline $\begin{array}{c}\text { Doctor's } \\
\text { Recommendation }\end{array}$ & 650 & & 318 & & & & & \\
\hline No & 95 & 76.0 & 30 & 24.0 & \multirow{2}{*}{5.098} & \multirow{2}{*}{0.024} & \multirow[b]{2}{*}{0.061} & \multirow{2}{*}{0.058} \\
\hline Yes & 555 & 65.8 & 288 & 34.2 & & & & \\
\hline Price & 650 & & 318 & & & & & \\
\hline No & 169 & 69.0 & 76 & 31.0 & \multirow{2}{*}{0.498} & \multirow{2}{*}{0.480} & \multirow{2}{*}{0.021} & \multirow{2}{*}{0.518} \\
\hline Yes & 481 & 66.5 & 242 & 33.5 & & & & \\
\hline
\end{tabular}

$\mathrm{Chi}^{2}$ : Chi-squared test for independence.

\subsection{Correlation between Population Characteristics and Acceptance towards Vaccination}

Chi-square and bivariate Spearman's correlation tests showed that females were less likely to accept COVID-19 vaccination than males $\left(X^{2}=51.78\right.$, Spearman's $r=-0.231$, $p<0.001)$, people living in rural areas were more accepting toward vaccination $\left(\mathrm{X}^{2}=7.07\right.$, Spearman's $r=0.085, p=0.008)$, and students and people with a job were more accepting of vaccination $\left(X^{2}=17.15\right.$, Spearman's $\left.r=0.102, p=0.002\right)$. On the other hand, different age groups, nationality, education, monthly income showed no significant correlations with vaccine acceptance (Table 5). 
Table 5. Correlation between Population characteristics and Acceptance towards Vaccination $(n=968)$. Bold type provide easier distinction between different Items.

\begin{tabular}{|c|c|c|c|c|c|c|c|c|}
\hline \multirow{2}{*}{ Characteristics } & \multicolumn{2}{|c|}{ Hesitant } & \multicolumn{2}{|c|}{ Accept } & \multirow{2}{*}{$\mathrm{Chi}^{2}$} & \multirow{2}{*}{$p$} & \multirow{2}{*}{ Spearman's $r$} & \multirow{2}{*}{$p$} \\
\hline & $n$ & $\%$ & $n$ & $\%$ & & & & \\
\hline Age Groups & 650 & & 318 & & \multirow{4}{*}{0.168} & \multirow{4}{*}{0.919} & \multirow{4}{*}{0.013} & \multirow{4}{*}{0.685} \\
\hline Below 30 & 456 & 67.6 & 219 & 32.4 & & & & \\
\hline $30-59$ & 186 & 66.2 & 95 & 33.8 & & & & \\
\hline Over 60 & 8 & 66.7 & 4 & 33.3 & & & & \\
\hline Gender & 650 & & 318 & & \multirow{4}{*}{51.779} & \multirow{4}{*}{0.000} & \multirow[b]{3}{*}{-0.231} & \multirow[b]{3}{*}{$<0.001$} \\
\hline Male & 198 & 53.4 & 173 & 46.6 & & & & \\
\hline Female & 452 & 75.7 & 145 & 24.3 & & & & \\
\hline Residency & 650 & & 318 & & & & & \\
\hline Urban & 525 & 69.3 & 233 & 30.7 & \multirow[b]{2}{*}{7.068} & \multirow[b]{2}{*}{0.008} & \multirow[b]{2}{*}{0.085} & \multirow[b]{2}{*}{0.008} \\
\hline Rural & 125 & 59.5 & 85 & 40.5 & & & & \\
\hline Nationality & 650 & & 318 & & & & & \\
\hline Egyptian & 621 & 67.4 & 300 & 32.6 & \multirow{2}{*}{0.664} & \multirow{2}{*}{0.415} & \multirow{2}{*}{0.026} & \multirow{2}{*}{0.416} \\
\hline Non-Egyptian & 29 & 61.7 & 18 & 38.3 & & & & \\
\hline Education & 650 & & 318 & & & & & \\
\hline Secondary or below & 22 & 71 & 9 & 29 & \multirow{4}{*}{0.68} & \multirow{4}{*}{0.712} & \multirow{4}{*}{0.026} & \multirow{4}{*}{0.424} \\
\hline Post-Secondary & 336 & 68 & 158 & 32 & & & & \\
\hline Tertiary & 292 & 65.9 & 151 & 34.1 & & & & \\
\hline Occupation & 650 & & 318 & & & & & \\
\hline Unemployed & 79 & 84 & 15 & 16 & \multirow{4}{*}{17.147} & \multirow{4}{*}{0.001} & & \\
\hline Part time & 52 & 63.4 & 30 & 36.6 & & & & \\
\hline Full time & 407 & 67.3 & 198 & 32.7 & & & 0.102 & 0.002 \\
\hline Student & 112 & 59.9 & 75 & 40.1 & & & & \\
\hline Marital status & 650 & & 318 & & & & & \\
\hline Single & 414 & 68.2 & 193 & 31.8 & & & & \\
\hline With partner & 236 & 65.4 & 125 & 34.6 & 0.822 & 0.365 & 0.029 & 0.365 \\
\hline Monthly Income & 650 & & 318 & & & & & \\
\hline Less than $5 \mathrm{k}$ & 87 & 71.3 & 35 & 28.7 & & & & \\
\hline $5 \mathrm{k}-10 \mathrm{k}$ & 222 & 66.9 & 110 & 33.1 & 1.122 & 0.571 & 0.025 & 0.429 \\
\hline More than $10 \mathrm{k}$ & 341 & 67.6 & 173 & 33.7 & & & & \\
\hline
\end{tabular}

$\mathrm{Chi}^{2}$ : Chi-squared test for independence.

\section{Discussion}

In 2019, the WHO identified ten significant threats to global health, including vaccine hesitancy and the risk of a pandemic [26]. Africa has now embarked on the biggest immunization drive in history to administer a COVID-19 vaccine to $60 \%$ of the population by June 2022 through the WHO-led COVAX facility [30]. This study assessed acceptance and attitudes regarding the COVID-19 vaccine in a sample of young to middle-aged well-educated adult Egyptians with an income of twice the average income and a slight overrepresentation of urban residency.

With a mean age of 29.11 years, the participants included in our study were younger than those investigated regarding vaccine hesitancy and attitudes toward COVID-19 vaccination in Egypt by El-Sokkary et al. [25] (37.6 years), similar to Omar and Hani [31] (29.35 years), and older than the medical students assessed by Saiedet al. [32] (20.24 years). The proportion of female participants was increased $(61.67 \%)$, which is in line with similar Egyptian studies (77.6\%), (65.2\%), (81.30\%), and (63.4\%) [31,33,34]. In contrast, Omar and Hani [31] studied a sample in which more than half of the participants (58.8\%) were males. As in our study, Omar and Hani [31] included more urban participants than rural participants (54.3\%). Marital status in our sample was mostly single $(62.71 \%)$, as in Omar and Hani (50\%) [31] and different from El-Sokkary et al. (10\%) [31].

In the present study, from March/April 2021, only a third (32.85\%) of participants were willing to accept the COVID-19 vaccine rapidly. This was similar to the previous report by El-Sokkary et al., targeting Egyptian healthcare workers in January 2021, in which $26.0 \%$ of the participants mentioned were willing to take the vaccine [31]. Fares et al. targeted healthcare 
workers in Egypt from December 2020 to January 2021. Here, 21\% of the participants were willing to take the vaccine [33]. Saied et al. targeted medical students at two Egyptian universities in January 2021, their acceptance rate to take the vaccine was 34.9\% [32], and Omar and Hani targeted Egyptian citizens living in Egypt aged 18 years and older from January to March 2021; in which 25\% mentioned being willing to take the vaccine [31]. According to our results, students have a higher vaccine acceptance rate $(40.1 \%)$, while Omar and Hani, who sampled earlier, found only a $12.8 \%$ vaccine acceptance rate, even among students [31]. In comparison, in other countries, the acceptance of COVID-19 vaccination during the COVID-19 pandemic was $91.3 \%$ among Chinese adults, even in March 2020 [24], 67\% among adults in the United States in May 2020 [34], 91.7\% among healthcare workers in Germany in February 2021 [35] and ranged from 71 to $78 \%$ among Australian adults in July-September 2020. In Italy, the vaccine acceptance rate among undergraduate students was very high (91.9\%) [35].

According to our results, 79 unemployed participants showed a relatively high rate of vaccine hesitancy $(84 \%)$, compared to the Omar and Hani study that had only $73(7.2 \%)$ of not working/housewives [31].

Our findings show that the potential factors associated with higher vaccine acceptance were rural residency, living with a partner, and being a secondary school student, which is similar to a report by Omar and Hani [31]. In our study, the vaccine price was not identified as a factor affecting the decision making regarding vaccination among participants. In contrast, the potential vaccine price affected the decision making in a previous study [31].

The Limitation and Strengths

Our study is the only study that collects data about vaccine hesitancy and acceptance during the third wave of the pandemic in Egypt, as Elgendy and Abdelrahim collected data in May 2021 [36]. The respondents were recruited with a non-random convenience sampling method in this study. There might be a limitation in generalizing the findings. The questionnaire was distributed in English. Therefore, there is a potential bias of missing the respondents with low English fluency. A substantial limitation of our study is that we did not know whether any of the participants had been vaccinated before the study. Furthermore, we did not know whether the participants had suffered from COVID-19 already. We believe that both factors could have influenced the results.

Our sample was smaller than the only two previous studies [32,33], while it was larger in sample size than almost all of the last Egyptian studies [31,33,36-38]. The drawbacks are that the questionnaire was administered online and in English, which might have caused some selection bias.

\section{Conclusions}

In summary, we conclude that there was a high rate of COVID-19 vaccine acceptance among the participants in our study compared with other Egyptian studies, despite the gender and geographic disparities observed in vaccine acceptance. Therefore, vaccination strategies should deliver adequate information to specific groups to achieve high vaccination coverage in Egypt.

Supplementary Materials: The following are available online at https://www.mdpi.com/article/10 .3390 /vaccines10010020/s1, File S1: Questionnaire.

Author Contributions: Conceptualization, M.E. and R.A.E.-A.; methodology R.A.E.-A., M.E., M.N.N.H. and M.A.K.; software K.T.D. and M.A.K.; validation, M.E., K.T.D., M.A.K. and R.R.M.; formal analysis, K.T.D., M.A.K.; investigation, R.A.E.-A., B.A.; resources, R.A.E.-A., M.E., B.A.; data curation, K.T.D., M.A.K.; writing—original draft preparation, M.E., K.T.D. and M.A.K.; writing—review and editing, M.E., M.A.K., K.T.D.; visualization, K.T.D.; supervision, R.R.M., M.N.N.H. and B.A.; project administration, M.E., B.A., R.R.M.; funding acquisition, NA. All authors have read and agreed to the published version of the manuscript.

Funding: This research received no external funding. 
Institutional Review Board Statement: Ethical approval was granted from the Research Ethics Committee from Asia Metropolitan University (Ethics Approval Number: AMU/FOM/NF 202115)

Informed Consent Statement: Before responding to the questionnaire, written informed consent was received online.

Data Availability Statement: The data at the basis of the findings of this study are available on request from the corresponding author.

Conflicts of Interest: The authors declare no conflict of interest.

\section{References}

1. WHO Coronavirus (COVID-19) Dashboard, WHO Coronavirus (COVID-19) Dashboard with Vaccination Data. Available online: https:/ / covid19.who.int/ (accessed on 24 September 2021).

2. Helmy, Y.A.; Fawzy, M.; Elaswad, A.; Sobieh, A.; Kenney, S.P.; Shehata, A.A. The COVID-19 Pandemic: A Comprehensive Review of Taxonomy, Genetics, Epidemiology, Diagnosis, Treatment, and Control. J. Clin. Med. 2020, 9, 1225. [CrossRef] [PubMed]

3. Wu, F.; Zhao, S.; Yu, B.; Chen, Y.M.; Wang, W.; Song, Z.G.; Hu, Y.; Tao, Z.W.; Tian, J.H.; Pei, Y.Y.; et al. A new coronavirus associated with human respiratory disease in China. Nature 2020, 579, 265-269. [CrossRef] [PubMed]

4. Cucinotta, D.; Vanelli, M. WHO declares COVID-19 a pandemic. Acta Biomed. 2020, 91, 157-160. [CrossRef]

5. COVID Live Update: 230,529,939 Cases and 4,725,868 Deaths from the Coronavirus-Worldometer. Available online: https: / / www.worldometers.info/coronavirus/ (accessed on 24 September 2021).

6. Vakili, K.; Fathi, M.; Pezeshgi, A.; Mohamadkhani, A.; Hajiesmaeili, M.; Rezaei-Tavirani, M.; Sayehmiri, F. Critical complications of COVID-19: A descriptive meta-analysis study. Rev. Cardiovasc. Med. 2020, 21, 433-442. [CrossRef]

7. Alvarado-Socarras, J.; Vesga-Varela, A.; Quintero-Lesmes, D.; Fama-Pereira, M.; Serrano-Diaz, N.; Vasco, M.; Carballo-Zarate, V.; Zambrano, L.; Paniz-Mondolfi, A.; Rodriguez-Morales, A. Perception of COVID-19 Vaccination Amongst Physicians in Colombia. Vaccines 2021, 9, 287. [CrossRef]

8. Sheikh, N.S.; Touseef, M.; Sultan, R.; Cheema, K.H.; Cheema, S.S.; Sarwar, A.; Siddique, H.Z. Understanding COVID-19 vaccine hesitancy in Pakistan: The paradigm of Confidence, Convenience, and Complacency; A Cross-sectional study. medRxiv 2021. [CrossRef]

9. Nicola, M.; Alsafi, Z.; Sohrabi, C.; Kerwan, A.; Al-Jabir, A.; Iosifidis, C.; Agha, M.; Agha, R. The socio-economic implications of the coronavirus pandemic (COVID-19): A review. Int. J. Surg. 2020, 78, 185-193. [CrossRef] [PubMed]

10. Kaddoura, M.; Allbrahim, M.; Hijazi, G.; Soudani, N.; Audi, A.; Alkalamouni, H.; Haddad, S.; Eid, A.; Zaraket, H. COVID-19 Therapeutic Options Under Investigation. Front. Pharmacol. 2020, 11, 1196. [CrossRef]

11. Hussein, I.E.; Echams, N.; Echams, S.; Sayegh, S.E.; Badran, R.; Eraad, M.; Egerges-Geagea, A.; Eleone, A.; Ejurjus, A. Vaccines Through Centuries: Major Cornerstones of Global Health. Front. Public Health 2015, 3, 269. [CrossRef] [PubMed]

12. Rodrigues, C.; Plotkin, S.A. Impact of Vaccines; Health, Economic and Social Perspectives. Front. Microbiol. 2020, 11, 1526. [CrossRef] [PubMed]

13. Ehreth, J. The value of vaccination: A global perspective. Vaccine 2003, 21, 4105-4117. [CrossRef]

14. Omer, S.B.; Yildirim, I.; Forman, H.P. Herd Immunity and Implications for SARS-CoV-2 Control. JAMA 2020, 324, 2095. [CrossRef]

15. Gong, W.; Aspatwar, A.; Wang, S.; Parkkila, S.; Wu, X. COVID-19 pandemic: SARS-CoV-2 specific vaccines and challenges, protection via BCG trained immunity, and clinical trials. Expert Rev. Vaccines 2021, 20, 857-880. [CrossRef] [PubMed]

16. Fine, P.; Eames, K.; Heymann, D.L. "Herd Immunity": A Rough Guide. Clin. Infect. Dis. 2011, 52, 911-916. [CrossRef] [PubMed]

17. Neumann-Böhme, S.; Varghese, N.E.; Sabat, I.; Barros, P.P.; Brouwer, W.; Van Exel, J.; Schreyögg, J.; Stargardt, T. Once we have it, will we use it? A European survey on willingness to be vaccinated against COVID-19. Eur. J. Health Econ. 2020, 21, 977-982. [CrossRef] [PubMed]

18. MacDonald, N.E.; Sage Working Group on Vaccine Hesitancy. Vaccine hesitancy: Definition, scope and determinants. Vaccine 2015, 33, 4161-4164. [CrossRef]

19. Schoch-Spana, M.; Brunson, E.K.; Long, R.; Ruth, A.; Ravi, S.J.; Trotochaud, M.; Borio, L.; Brewer, J.; Buccina, J.; Connell, N.; et al. The public's role in COVID-19 vaccination: Human-centered recommendations to enhance pandemic vaccine awareness, access, and acceptance in the United States. Vaccine 2021, 39, 6004-6012. [CrossRef]

20. French, J.; Deshpande, S.; Evans, W.; Obregon, R. Key Guidelines in Developing a Pre-Emptive COVID-19 Vaccination Uptake Promotion Strategy. Int. J. Environ. Res. Public Health 2020, 17, 5893. [CrossRef] [PubMed]

21. Egypt: WHO Coronavirus Disease (COVID-19) Dashboard with Vaccination Data I WHO Coronavirus (COVID-19) Dashboard With Vaccination Data. Available online: https://covid19.who.int/region/emro/country/eg (accessed on 24 September 2021).

22. Egypt: The Latest Coronavirus COUNTS, Charts and Maps. Available online: https://graphics.reuters.com/world-coronavirustracker-and-maps / countries-and-territories/egypt/ (accessed on 24 September 2021).

23. Gallè, F.; Sabella, E.A.; Roma, P.; De Giglio, O.; Caggiano, G.; Tafuri, S.; Da Molin, G.; Ferracuti, S.; Montagna, M.T.; Liguori, G.; et al. Knowledge and Acceptance of COVID-19 Vaccination among Undergraduate Students from Central and Southern Italy. Vaccines 2021, 9, 638. [CrossRef] [PubMed] 
24. Wang, J.; Jing, R.; Lai, X.; Zhang, H.; Lyu, Y.; Knoll, M.D.; Fang, H. Acceptance of COVID-19 Vaccination during the COVID-19 Pandemic in China. Vaccines 2020, 8, 482. [CrossRef] [PubMed]

25. El-Sokkary, R.H.; El Seifi, O.S.; Hassan, H.M.; Mortada, E.M.; Hashem, M.K.; Gadelrab, M.R.M.A.; Tash, R.M.E. Predictors of COVID-19 vaccine hesitancy among Egyptian healthcare workers: A cross-sectional study. BMC Infect. Dis. 2021, $21,762$. [CrossRef]

26. World Health Organization (WHO). Ten Threats to Global Health in 2019. 2019. Available online: https://www.who.int/newsroom/spotlight/ten-threats-to-global-health-in-2019 (accessed on 26 September 2021).

27. Egypt Population (2021) Live-Countrymeters. Available online: https:/ / countrymeters.info/en/Egypt (accessed on 27 October 2021).

28. Egypt: Total Urban Population by Governorate 2021 | Statista. Available online: https://www.statista.com/statistics/1229861/ urban-population-of-egypt-by-governorate/ (accessed on 27 October 2021).

29. CAPMAS: Household Annual Income Increased to EGP 69000. Available online: https://see.news/capmas-household-annualincome-increased-to-egp-6900011/ (accessed on 27 October 2021).

30. Otu, A.; Osifo-Dawodu, E.; Atuhebwe, P.; Agogo, E.; Ebenso, B. Beyond vaccine hesitancy: Time for Africa to expand vaccine manufacturing capacity amidst growing COVID-19 vaccine nationalism. Lancet Microbe 2021, 2, e347-e348. [CrossRef]

31. Omar, D.I.; Hani, B.M. Attitudes and intentions towards COVID-19 vaccines and associated factors among Egyptian adults. J. Infect. Public Health 2021, 14, 1481-1488. [CrossRef]

32. Saied, S.M.; Saied, E.M.; Kabbash, I.A.; Abdo, S.A.E. Vaccine hesitancy: Beliefs and barriers associated with COVID-19 vaccination among Egyptian medical students. J. Med. Virol. 2021, 93, 4280-4291. [CrossRef] [PubMed]

33. Fares, S.; Elmnyer, M.M.; Mohamed, S.S.; Elsayed, R. COVID-19 Vaccination Perception and Attitude among Healthcare Workers in Egypt. J. Prim. Care Community Health 2021, 12, 21501327211013303. [CrossRef]

34. Malik, A.A.; McFadden, S.M.; Elharake, J.; Omer, S.B. Determinants of COVID-19 vaccine acceptance in the US. EClinicalMedicine 2020, 26, 100495. [CrossRef]

35. Holzmann-Littig, C.; Braunisch, M.; Kranke, P.; Popp, M.; Seeber, C.; Fichtner, F.; Littig, B.; Carbajo-Lozoya, J.; Allwang, C.; Frank, T.; et al. COVID-19 Vaccination Acceptance and Hesitancy among Healthcare Workers in Germany. Vaccines 2021,9 , 777. [CrossRef] [PubMed]

36. Elgendy, M.O.; Abdelrahim, M.E.A. Public awareness about coronavirus vaccine, vaccine acceptance, and hesitancy. J. Med. Virol. 2021, 93, 6535-6543. [CrossRef] [PubMed]

37. Mohamed-Hussein, A.A.; Makhlouf, H.; Abd El Aal, H.; Kholief, K.; Saad, M.M.; Abdellal, D.A. A national survey of potential acceptance of COVID-19 vaccines in healthcare workers in Egypt. medRxiv 2021. [CrossRef]

38. Qunaibi, E.; Basheti, I.; Soudy, M.; Sultan, I. Hesitancy of Arab Healthcare Workers towards COVID-19 Vaccination: A Large-Scale Multinational Study. Vaccines 2021, 9, 446. [CrossRef] 